\title{
Invasive Rhinosinusitis due to Alternaria alternata and Rhizopus arrhizus Mixed Infection: A Case Report and Review
}

\author{
Brijesh Sharma, ${ }^{1,}$ Ulka Kamble, ${ }^{1}$ Gopal Ghosh, ${ }^{1}$ Akhilandeswari Prasad, ${ }^{2}$ and Anuradha Chowdhary ${ }^{3}$ \\ ${ }^{1}$ Department of Medicine, Dr. RML Hospital \& PGIMER, New Delhi, India \\ ${ }^{2}$ Department of Radiology, Dr. RML Hospital \& PGIMER, New Delhi, India \\ ${ }^{3}$ Department of Medical Mycolgy,Vallabh Bhai Patel Chest Institute, Institute, University Of Delhi, India \\ "Corresponding author: Brijesh Sharma, Department of Medicine, Dr. RML Hospital \& PGIMER, New Delhi, India. Tel: +91-9013262275, E-mail: brijsushma@gmail.com
}

Received 2016 September 25; Revised 2016 October 14; Accepted 2016 October 14.

\begin{abstract}
Introduction: Rhizopuse Sp. are common infectious agents of invasive rhinosinusitis. Though Alternaria is known to cause allergic rhinosinusitis, invasive sinusitis because of Alternaria Sp. is rare. Coinfections with bacteria and fungus causing rhinosinusitis have been reported as have the Rhizopus infection with other fungus such as Aspergillus, Candida, and Exserohillum. However Rhizopus coinfection with Alternaria has not been reported to the best of our knowledge.

Case Presentation: A sixty-year- old woman was admitted with periorbital pain, swelling and complete restriction of movement of her right eye. She had diabetes mellitus for fifteen years. Diagnosis of invasive sinusitis was confirmed by hyperintensities in her right maxillary and bilateral ethmoid sinuses on the MRI on her brain and demonstration of hyphal forms from sinus mucosa. Culture confirmed the presence of Alternariaalternata and Rhizopus arrhizus. Patient responded to treatment with Amphotercin B and had complete resolution.

Conclusions: Co-infection with bacteria and mixed fungal infection should be looked for as treatment strategies may differ with different organisms. Presumptive treatment should include agents, which can cover the broadest possible range of organism known to cause invasive sinusitis.
\end{abstract}

Keywords: Sinusitis, Coinfection, Alternariosis, Mucormycosis

\section{Introduction}

Rhizopuses Sp. are common infectious agents of invasive rhinosinusitis (1). Though Alternaria is known to cause allergic rhinosinusitis, invasive sinusitis because of $\mathrm{Al}$ ternaria Sp. is less common (2). Coinfections with bacteria and fungus causing invasive rhinosinusitis (3) have been reported as have been Rhizopus infection with other fungus such as Aspergillus, Candida, and Exserohillum. However Rhizopus coinfection with Alternaria has not been reported to the best of our knowledge. We report a case of Rhizopus and Alternaria coinfection causing invasive rhinosinusitis. Patients consent was taken to report the case.

\section{Case Presentation}

A 60-year-old female with diabetes mellitus for the last 15 years was presented to the medical outpatient department of a tertiary care teaching hospital in New Delhi on August 18, 2013 with complaints of her right periorbital swelling, pain in the right eye and inability to move the right eye for last 4 to 5 days. Initially she developed pain and mild swelling around the right eye with double vision but over the next 4 - 5 days, she developed complete restriction of movement in the right eye, with increased periorbital puffiness and pain over the right eye. She had no history of fever, diminution of vision, redness or watering from her eye. She had no history of recurrent rhinosinusitis. On her physical examination, she had swelling around the right eye and movement in all directions were absent. An ophthalmological consultation conferred a probable case of orbital cellulitis but the possibility of early cavernous sinus thrombosis could not be ruled out. In view of the probability of cavernous sinus thrombosis, intravenous antibiotics, Ceftriaxone $2 \mathrm{gm}$ intravenous twice a day and Vancomycin 1 gram intravenous twice a day were initiated. On the next day after admission she developed pain around the right half of her face, when exanimated, she had diminished pain and touch sensation around the distribution of ophthalmic (V1), maxillary (V2) and mandibular (V3) nerve.

A complete blood count revealed haemoglobin of 13 gm $\%$ and a total count of 17,000 cells $/ \mathrm{mm}^{3}$. The differential count revealed polymorphonuclear leukocytosis (neutrophils $90 \%$, lymphocytes $8 \%$, monocytes $1 \%$, eosinophil 1\%) and ESR $25 \mathrm{~mm}$. Total IgE was $25 \mathrm{kU} / \mathrm{L}$. Biochemical investigations revealed fasting blood sugar $134 \mathrm{mg} / \mathrm{dL}$ with

Copyright ( ) 2016, Infectious Diseases and Tropical Medicine Research Center. This is an open-access article distributed under the terms of the Creative Commons Attribution-NonCommercial 4.0 International License (http://creativecommons.org/licenses/by-nc/4.0/) which permits copy and redistribute the material just in noncommercial usages, provided the original work is properly cited. 
post-prandial blood sugar $182 \mathrm{mg} / \mathrm{dL}$. Blood urea nitrogen levels and serum levels of creatinine, bilirubin, alanine aminotransferase aspartate aminotransferase, alkaline phosphate, sodium and potassium were normal. MRI on the brain including an orbit showed hyperintensties in right maxillary and bilateral ethmoid sinuses on T2 axial sequences (Figure $1 \mathrm{~A}$ and $\mathrm{B}$ ).

The MR venography scan was normal. We kept the possibility of invasive sinusitis and a direct nasal endoscopy was done, which revealed inflamed nasal mucosae around the meatus of the sinuses and of the right maxillary sinus. Nasal endoscopy guided mucosal biopsy was taken from the right maxillary sinus and from the nasal mucosae around the meatus of sinuses and sent for fungal staining and culture at the medical mycology, V. P. Chest Institute. Tissue specimen was processed for direct $\mathrm{KOH}$ wet mount and culture on routine mycological media. Direct microscopy of the $\mathrm{KOH}$ wet mount of the digested tissue of both from maxillary sinus and nasal mucosae revealed broad aseptate hyaline hyphae branching at acute angle and in addition a few branched septate dematiaceous hyphae (Figure 2) were also observed.

Culture on sabourauds dextrose agar (SDA) incubated at $280^{\circ} \mathrm{C}$ revealed growth of Rhizopus arrhizus and Alterneria alternata species. The isolates were purified and identified by sequencing of internal transcribed spacer (ITS) region using primers ITS1/ITS4. The sequences were aligned and the species identification was performed using Gene Bank basic local alignment search tool (BLAST). Intravenous amphotericin B deoxycholate (dosage $50 \mathrm{mg}$ daily) antifungal therapy begins on the third day of admission. Gradually pain and periorbital swelling around the right eye diminished after a week of therapy and after two weeks of therapy the right eye movement was resumed. Initially abduction movement came, and then gradually the elevation and depression movements in the abducted eye also resumed. At the time of discharge, after 6 weeks of treatment, on October 2013, she had complete movement in all directions except the abduction and elevation in the adducted eye (Figure 3A and C). Her pain and periorbital swelling completely subsided and pain around the right half of face completely recovered. On the follow up, in the OPD, after a month she had normal movement in her right eye in all directions (Figure $3 \mathrm{~B}$ and $\mathrm{D}$ ). A repeated MRI scan showed complete resolution of hyper intensities in the right maxillary sinus (Figure $1 \mathrm{C}$ ) and bilateral ethmoid sinuses (Figure 1D) on T2 axial images. The patient has been following up in the outpatient department and by August 2015 she had fully recovered with full range of eye movement.

\section{Discussion}

This report highlights the occurrence of invasive sinus infections due to species of Mucorales and black fungi. Rhizopus sp. is a common infectious agent in invasive rhinosinusitis. However, species of Alternaria causing invasive rhinosiusitis per se are rare although allergic fungal sinusitis due to species of Alternaria is well known. Alternaria is a dematiaceous fungi causing a disease in cereals. Fungal growth initially causes surface pigmentation, followed by a breakdown of the seed (4-6). Though as prevalent in the environment as Aspergillus and Fusarium, Alternaria is not as commonly found in human infections. Alternaria alternata and Alternaria tenuissima are the most frequent agents of human alternosis (7).

The genus Alternaria contains several species of dematiaceous hyphomycetes that are implicated in opportunistic human diseases. Cutaneous and subcutaneous alternosis in immunosuppressed individuals is the most common presentation (8-11). The major risk factors for cutaneous/subcutaneous diseases are organ transplantation and Cushing's syndrome (12). While bone marrow recipients are at risk for sinusitis, Ocular disease is seen in individuals exposed to soil and garbage and nail involvement is rarely reported. There are also few reports of allergic fungal sinusitis $(13,14)$. Further bacterial coinfection with Psuedomonas has been reported in chronic invasive rhinocerebral mucormycosis (3). Fungal coinfection has also been reported. The organism have been Rhizopus with Aspergillus, Candida and Exserohillum. Mucorale with Aspergillus and a case of triple infection with Mucorale, Candida and Rhizopus has also been reported $(15,16)$.

Our patient was a known case of diabetes, thus she was immunosuppressed and predisposed to develop fungal infection. Furthermore, as our patient did not have any history of allergic rhinitis or sinusitis and her total IgE level was $25 \mathrm{kU} / \mathrm{L}$, the diagnosis of allergic fungal sinusitis was ruled out. Our patient had pain and periorbital swelling with complete restriction of movement in the right eye. This along with presence of hyperintensties in the right maxillary sinus, bilateral ethmoid sinuses and evidence of hyphal form within sinus mucosa were diagnostic of chronic invasive fungal sinusitis (17). We also repeatedly isolated multiple colonies of both the fungi in debrided tissue on culture confirming the diagnosis of Alternaria and Rhizopus co infection in invasive sinusitis. Complete opthalmoplegia in sinusitis occurs because of either orbital abscess or cavernous thrombosis. Our patient did not have either on the MRI imaging. However inflammation of orbital contents may also lead to limitation of eye movement. Spread from ethmoid and maxillary sinuses can occur through retrograde thrombophelebitis (18). This 

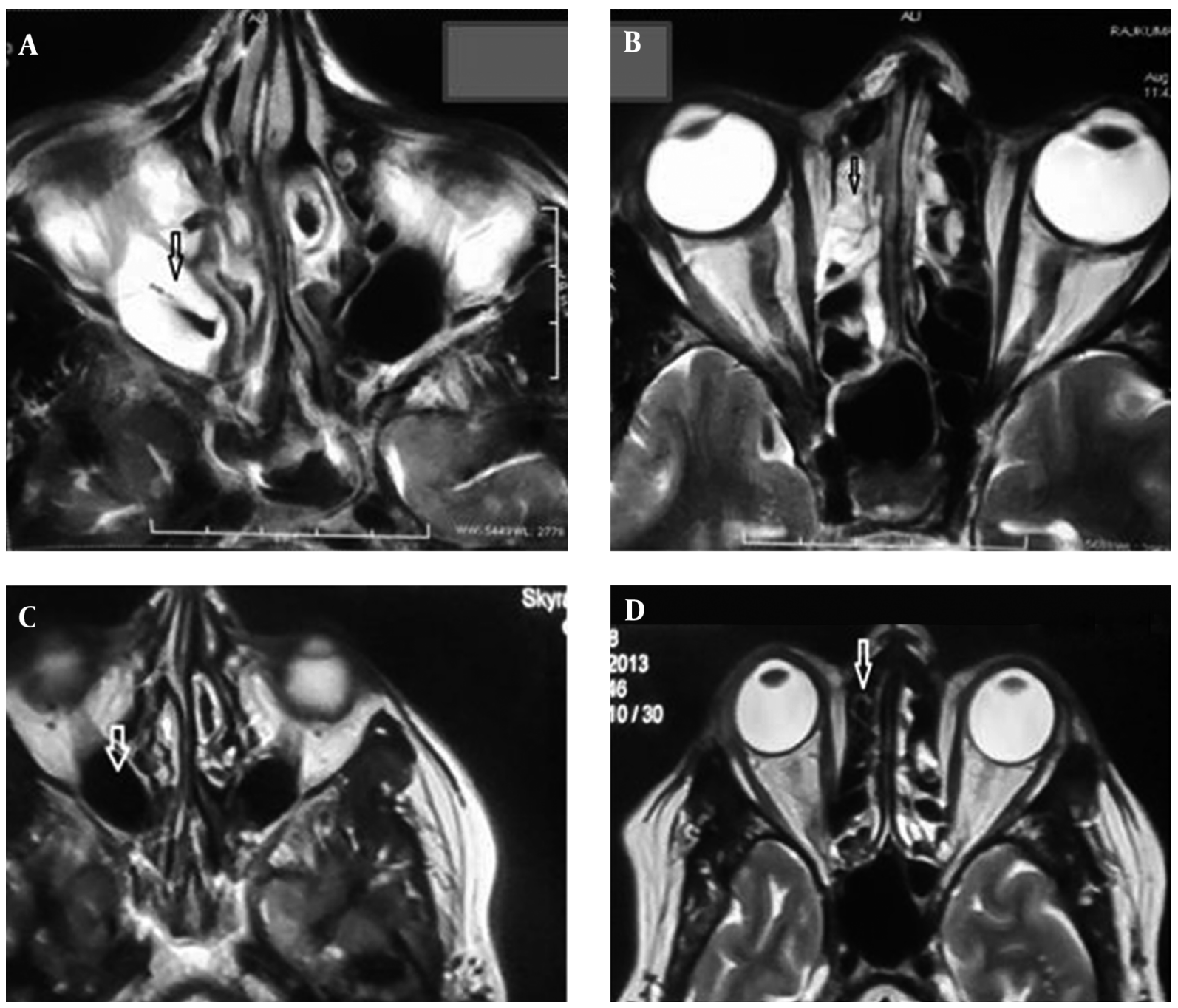

In lower panel post treatment: T2 axial MR sequences shows significant resolution in (C) right maxillary sinus and (D) bilateral ethmoid sinuses (see arrow).

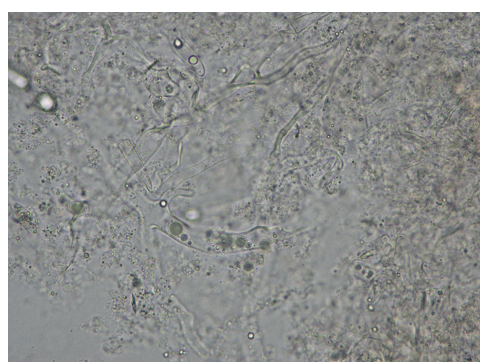

Figure 2. KOH Mount Showing Broad Aseptate Hyaline Hyphae Branching at Acute Angle and in Addition Few Branched Septate Dematiaceous Hyphae (400 X) early invasion may not be visible on radiological examination. This could probably be the reason for opthalmoplegia in our case. The literature reviewed from 1933 to 2008 revealed 210 reported cases of Alternaria infections in humans. The clinical manifestations were cutaneous and subcutaneous infections (74.3\%), followed by oculomycosis (9.5\%), invasive and non-invasive rhinosinusitis (8.1\%) and onychomycosis (8.1\%). In general, alternariosis shows a good response to drugs like itraconazole, amphotericin B. Posaconazole and voriconazole which are effective options. Voriconazole is particularly useful for ocular infection (6). However, since Rhizopus is more likely to become disseminated on treatment with voriconazole and our case had a mixed Rhizopus arrhizus and Alternaria fungal infec- 

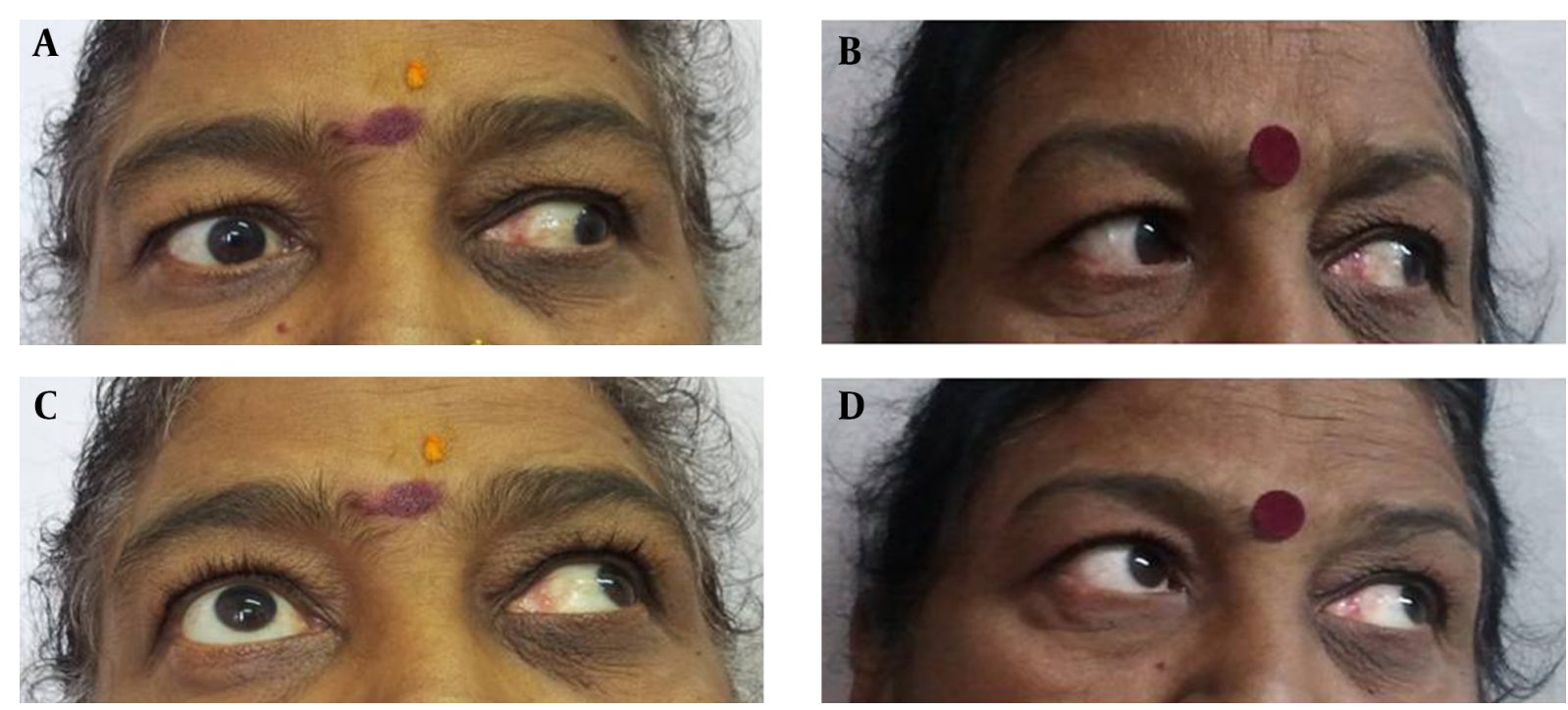

Left column, A, and C are mid treatment showing restriction of adduction and elevation of adducted right eye respectively. Right column, B and D show full recovery of adduction and elevation of adducted eye

tion, we treated the patient with Amphotericin B deoxycholate. The patient recovered completely after treatment with Amphotericin B.

\subsection{Conclusion}

Dematiaceous fungi are increasingly being reported for different diseases. The case reported here is rare because Alternaria, a dematiaceous fungus, is not a common organism causing invasive rhinosinusitis. Further Mixed invasive rhinosinusitis with Alternaria has not been reported to the best of our knowledge. Signs of invasion in orbit may not be visible on radiological examination in early invasive sinusitis. When suspected on clinical grounds, fungal culture and histopathological examination is a must in invasive sinusitis. Co-infection with bacteria and mixed fungal infection should be looked for as treatment strategies may differ with different organisms. Presumptive treatment should include agents, which can cover the broadest possible range of organism known to cause invasive sinusitis.

\section{References}

1. Michael RC, Michael JS, Ashbee RH, Mathews MS. Mycological profile of fungal sinusitis: An audit of specimens over a 7-year period in a tertiary care hospital in Tamil Nadu. Indian J Pathol Microbiol. 2008;51(4):493-6. doi: 10.4103/0377-4929.43738. [PubMed: 19008573].

2. Malani PN, Kauffman CA. Invasive and Allergic Fungal Sinusitis. Curr Infect Dis Rep. 2002;4(3):225-32. [PubMed: 12015915].
3. Dimaka K, Mallis A, Naxakis SS, Marangos M, Papadas TA, Stathas T, et al. Chronic rhinocerebral mucormycosis: a rare case report and review of the literature. Mycoses. 2014;57(11):699-702. doi: 10.1111/myc.12219. [PubMed: 25039925].

4. Hasan HA. Phytotoxicity of pathogenic fungi and their mycotoxins to cereal seedling viability. Mycopathologia. 1999;148(3):149-55. doi: 10.1023/A:1007164617175. [PubMed: 11189766].

5. Li F, Yoshizawa T. Alternaria mycotoxins in weathered wheat from China. J Agric Food Chem. 2000;48(7):2920-4. doi: 10.1021/jfo000171. [PubMed: 10898645].

6. Morrison VA, McGlave PB. Mucormycosis in the BMT population. Bone Marrow Transplant. 1993;11(5):383-8. [PubMed: 8504272].

7. Brandt ME, Warnock DW. Epidemiology, clinical manifestations, and therapy of infections caused by dematiaceous fungi. J Chemother. 2003;15 Suppl 2:36-47. doi: 10.1179/joc.2003.15.Supplement-2.36. [PubMed: 14708965].

8. Gene J, Azon-Masoliver A, Guarro J, Ballester F, Pujol I, Llovera M, et al. Cutaneous phaeohyphomycosis caused by Alternaria longipes in an immunosuppressed patient. J Clin Microbiol. 1995;33(10):2774-6. [PubMed: 8567925].

9. Pastor FJ, Guarro J. Alternaria infections: laboratory diagnosis and relevant clinical features. Clin Microbiol Infect. 2008;14(8):734-46. doi: 10.1111/j.1469-0691.2008.02024.x. [PubMed: 18727797].

10. Pereiro M, Pereiro Ferreiros MM, De Hoog GS, Toribio J. Cutaneous infection caused by Alternaria in patients receiving tacrolimus. Med Mycol. 2004;42(3):277-82. doi: 10.1080/13693780310001610047. [PubMed: 15283243].

11. Wiest PM, Wiese K, Jacobs MR, Morrissey AB, Abelson TI, Witt W, et al. Alternaria infection in a patient with acquired immunodeficiency syndrome: case report and review of invasive alternaria infections. Rev Infect Dis. 1987;9(4):799-803. doi:10.1093/clinids/9.4.799. [PubMed: 3326127].

12. Gilaberte M, Bartralot R, Torres JM, Reus FS, Rodriguez V, Alomar A, et al. Cutaneous alternariosis in transplant recipients: clinicopathologic review of 9 cases. J Am Acad Dermatol. 2005;52(4):653-9. doi: 10.1016/j.jaad.2004.10.875. [PubMed: 15793517]. 
13. Bartynski JM, McCaffrey TV, Frigas E. Allergic fungal sinusitis secondary to dermatiaceous fungi-Curvularia lunata and Alternaria. Otolaryngol Head Neck Surg. 1990;103:32-9. doi: 10.1177/019459989010300105.

14. Chowdhary A, Agarwal K, Randhawa HS, Kathuria S, Gaur SN, Najafzadeh MJ, et al. A rare case of allergic bronchopulmonary mycosis caused by Alternaria alternata. Med Mycol. 2012;50(8):890-6. doi: 10.3109/13693786.2012.682320. [PubMed: 22563857].

15. Talmi YP, Goldschmied-Reouven A, Bakon M, Barshack I, Wolf M Horowitz Z, et al. Rhino-orbital and rhino-orbito-cerebral mucormycosis. Otolaryngol Head Neck Surg. 2002;127(1):22-31. doi: 10.1067/mhn.2002.126587. [PubMed: 12161726].
16. Monroe MM, McLean M, Sautter N, Wax MK, Andersen PE, Smith TL, et al. Invasive fungal rhinosinusitis: a 15-year experience with 29 patients. Laryngoscope. 2013;123(7):1583-7. doi: 10.1002/lary.23978. [PubMed: 23417294].

17. deShazo RD, O'Brien M, Chapin K, Soto-Aguilar M, Gardner L, Swain R. A new classification and diagnostic criteria for invasive fungal sinusitis. Arch Otolaryngol Head Neck Surg. 1997;123(11):1181-8. doi: 10.1001/archotol.1997.01900110031005. [PubMed: 9366697].

18. El-Beltagy Y, Hamdy TAH, Hasaballah MS. Orbital complications following sinusitis still a problem: Our experience and results. Egyptian J Ear, Nose, Throat Allied Sci. 2014;15:189-95. 